\title{
Tactile information improves visual object discrimination in kea, Nestor notabilis, and capuchin monkeys, Sapajus spp.
}

\author{
Paola Carducci a, b, *, Raoul Schwing ${ }^{\text {c, d }}{ }^{\text {, Ludwig Huber }}{ }^{\text {c, d, }}{ }^{\text {, Valentina Truppa }}{ }^{\text {a, ** }}$ \\ a Institute of Cognitive Sciences and Technologies, National Research Council (CNR), Rome, Italy \\ ${ }^{\mathrm{b}}$ Environmental and Evolutionary Biology PhD Program, Department of Environmental Biology, Sapienza University of Rome, Rome, Italy \\ ${ }^{\mathrm{c}}$ Comparative Cognition, Messerli Research Institute, University of Veterinary Medicine Vienna, Medical University Vienna, University of Vienna, Vienna, \\ Austria \\ ${ }^{\mathrm{d}}$ Haidlhof Research Station, Bad Vöslau, Austria
}

\section{A R T I C L E I N F O}

\section{Article history:}

Received 17 July 2017

Initial acceptance 25 August 2017

Final acceptance 27 October 2017

MS. number: 17-00545R

\section{Keywords:}

learning

mountain parrots

multisensory integration

New World monkeys

object discrimination

tactile memory

visuotactile integration
In comparative visual cognition research, the influence of information acquired by nonvisual senses has received little attention. Systematic studies focusing on how the integration of information from sight and touch can affect animal perception are sparse. Here, we investigated whether tactile input improves visual discrimination ability of a bird, the kea, and capuchin monkeys, two species with acute vision, and known for their tendency to handle objects. To this end, we assessed whether, at the attainment of a criterion, accuracy and/or learning speed in the visual modality were enhanced by haptic (i.e. active tactile) exploration of an object. Subjects were trained to select the positive stimulus between two cylinders of the same shape and size, but with different surface structures. In the Sight condition, one pair of cylinders was inserted into transparent Plexiglas tubes. This prevented animals from haptically perceiving the objects' surfaces. In the Sight and Touch condition, one pair of cylinders was not inserted into transparent Plexiglas tubes. This allowed the subjects to perceive the objects' surfaces both visually and haptically. We found that both kea and capuchins (1) showed comparable levels of accuracy at the attainment of the learning criterion in both conditions, but (2) required fewer trials to achieve the criterion in the Sight and Touch condition. Moreover, this study showed that both kea and capuchins can integrate information acquired by the visual and tactile modalities. To our knowledge, this represents the first evidence of visuotactile integration in a bird species. Overall, our findings demonstrate that the acquisition of tactile information while manipulating objects facilitates visual discrimination of objects in two phylogenetically distant species.

๑ 2017 The Association for the Study of Animal Behaviour. Published by Elsevier Ltd. All rights reserved.
In their natural environment organisms receive information through multiple sensory channels. This input is combined into integrated percepts by multisensory systems in which different senses work in parallel (Stein \& Meredith, 1993). Object exploration therefore allows the simultaneous acquisition and integration of information gained by different senses. Consequently, at least in species that tend to explore objects by handling them, the information gained from the sense of touch is potentially as important as visual information to interact with surrounding objects.

Interest in the interaction between sight and touch dates back to early research in the study of visual behaviour (e.g. Berkeley, 1709);

\footnotetext{
* Correspondence: P. Carducci, Institute of Cognitive Sciences and Technologies, National Research Council (CNR), Via Ulisse Aldrovandi 16/B, 00197 Rome, Italy.

** Correspondence: V. Truppa, Institute of Cognitive Sciences and Technologies, National Research Council (CNR), Via Ulisse Aldrovandi 16/B, 00197 Rome, Italy.

E-mail addresses: paola.carducci@uniroma1.it (P. Carducci), valentina.truppa@ istc.cnr.it (V. Truppa).
}

however, experimental work on visuotactile integration has expanded only in the last few decades and has focused almost exclusively on humans (Gallace \& Spence, 2014). Ernst and Banks (2002), in their maximum likelihood estimate model, proposed that humans combine parallel information from visual and haptic senses in a statistically optimal fashion to maximize the precision of the final encoding. Several studies have demonstrated that human subjects trained, either visually or haptically, to identify objects or to recognize categories of objects, when tested in the untrained sensory modality, can transfer knowledge of object identity (e.g. Lacey, Peters, \& Sathian, 2007; Lawson, 2009; Norman, Norman, Clayton, Lianekhammy, \& Zielke, 2004) and knowledge of object category (Wallraven, Bülthoff, Waterkamp, van Dam, \& Gaißert, 2014; Yildirim \& Jacobs, 2013) between these two sensory modalities. Particularly, training adults to discriminate shape categories by touch also improved their ability to visually discriminate the same stimuli and vice versa (Wallraven et al., 2014). 
Cross-modal transfer of information between visual and tactile systems has been investigated in a small number of nonhuman species, mainly using matching-to-sample tasks (for a review see Cloke, Jacklin, \& Winters, 2015). Davenport and Rogers (1970) provided one of the first demonstrations of cross-modal recognition of stimuli in nonhuman species by testing chimpanzees, Pan troglodytes, and orang-utans, Pongo sp., in a visuotactile matching-to-sample task. Individuals were required to view a sample object and select one of two visually concealed objects (comparison stimuli) by touch. Subjects trained to match a set of repeatedly presented objects succeeded afterwards in matching (1) novel objects that they had never seen before (Davenport \& Rogers, 1970) and (2) objects presented with delay intervals between the presentation of the sample object and the comparison stimuli (Davenport, Rogers, \& Russell, 1975). Similar results were shown in monkeys (Cowey \& Weiskrantz, 1975; Elliott, 1977; Petrides \& Iversen, 1976; Weiskrantz \& Cowey, 1975) and more recently in rats, Rattus sp. (Reid, Jacklin, \& Winters, 2012, 2013; Winters \& Reid, 2010). Overall, these studies demonstrated that cross-modal transfer between vision and touch exists in mammalian species, such as chimpanzees, orang-utans, rhesus monkeys, Macaca mulatta, capuchin monkeys, Sapajus apella, and rats. Aside from studies on mammalian species, cross-modal transfer between vision and touch is mostly unexplored. Moreover, it is still unclear whether, compared to conditions where an animal only has visual cues, visual discrimination ability is enhanced in conditions where an animal can acquire tactile information.

Thus, we considered it important to assess whether species that manipulate edible and nonedible items can use haptic exploration and tactile memories when they need to visually identify objects in the future. This could mean that tactile memory is particularly advantageous since visual discrimination allows individuals to select objects from a distance, before touching them. Moreover, since object discrimination tasks are commonly used in the study of cognitive domains, it is important to evaluate from a methodological point of view whether being able to exploit tactile information might improve object discrimination abilities.

Learning effects, possibly due to tactile information acquired during manipulation, have been reported in two phylogenetically distant vertebrate species: kea, an alpine parrot species (O'Hara, Huber, \& Gajdon, 2015), and capuchin monkeys, neotropical primates (Truppa, Carducci, Trapanese, \& Hanus, 2015). O'Hara et al. (2015), demonstrated that kea required significantly fewer trials to learn to discriminate objects than their 2D images. Similarly, Truppa et al. (2015) reported that capuchins tested in a visual discrimination task achieved a learning criterion faster when they had the opportunity to manipulate stimuli than when images were presented on a computer screen. Both kea and capuchins have acute vision and a high proclivity to handle and explore objects with their limbs, beaks and mouths (Diamond \& Bond, 1999; Fragaszy, Visalberghi, \& Fedigan, 2004; O'Hara et al., 2017); thus, it has been hypothesized that both species benefit from tactile information about stimuli. However, the results of O'Hara et al. (2015) and Truppa et al. (2015) could not rule out that these effects were attributable to the types of stimuli that they used in their studies. In fact, aside from the acquisition of tactile information, from a visual perceptual standpoint 2D images carry less visual information than 3D stimuli such as objects. Therefore, to determine whether previous findings on kea and capuchins can be ascribed to additional tactile information, it is important to use the same type of stimuli and control for the opportunity to gain tactile information.

Here we used a two-alternative forced-choice task to assess whether tactile information enhances the visual discrimination capability of kea and capuchin monkeys and affects their performance in an object discrimination task. To our knowledge, this represents the first attempt to evaluate visuotactile integration in a bird species. Individuals were trained to select one of two objects, each of which had a different surface structure. Only one object contained a food reward. Subjects made a choice based on visual cues, and then were allowed to manipulate the chosen object to search for a hidden food item. During the manipulation phase, the opportunity to gain tactile information on the surface of the object was controlled by using objects designed to allow (Sight and Touch condition) or prevent (Sight condition) the acquisition of tactile information that could be used to discriminate between the objects. We hypothesized that both kea and capuchins will take advantage of this tactile information, and thus perform better in the Sight and Touch than the Sight condition. In addition, this study allowed us to evaluate whether these two species benefit from tactile information in a comparable way.

\section{EXPERIMENT ON KEA}

\section{Methods}

\section{Subjects and housing conditions}

We tested eight kea, mountain parrots endemic to New Zealand's South Island (Diamond \& Bond, 1999): six males and two females (Table 1). All birds were adults (5-16 years old) born in captivity. They were permanently kept in a well-established group of 22 members housed in a large and environmentally enriched outdoor aviary (52 $\times 10 \mathrm{~m}$ and $6 \mathrm{~m}$ high) at the Haidlhof Research Station, Bad Vöslau, Lower Austria. The aviary was equipped with sand on the ground, hanging branches for perching, two ponds, wooden sleeping and breeding shelters, feeding tables and a variety of enrichment devices that were regularly replaced. Fresh water and bathing opportunities were provided ad libitum. Food was distributed three times daily and consisted of fruits, vegetables, seeds, eggs, meat or cream cheese depending on specific individual diets. The aviary included two breeding compartments and an area that could be divided into seven compartments by sliding wiremesh doors. Two of these compartments (the experimental

Table 1

Individual data concerning sex, age and performance of kea and capuchins

\begin{tabular}{lllllll}
\hline Subjects & Sex & $\begin{array}{l}\text { Age } \\
\text { (years) }\end{array}$ & $\begin{array}{l}\text { Learning } \\
\text { speed (S\&T) }\end{array}$ & $\begin{array}{l}\text { Learning } \\
\text { speed }(\mathrm{S})\end{array}$ & $\begin{array}{l}\text { Accuracy } \\
\text { score (S\&T) }\end{array}$ & $\begin{array}{l}\text { Accuracy } \\
\text { score (S) }\end{array}$ \\
\hline Kea & & & & & & \\
Anu & M & 8 & 112 & 184 & 91.67 & 95.83 \\
John & M & 16 & 184 & 232 & 95.83 & 91.67 \\
Kermit & M & 11 & 112 & 240 & 91.67 & 100.00 \\
Paul & M & 5 & 96 & 216 & 100.00 & 91.67 \\
Pick & M & 11 & 112 & 192 & 95.83 & 95.83 \\
Roku & M & 7 & 112 & 216 & 91.67 & 91.67 \\
Coco & F & 8 & 120 & 216 & 87.50 & 87.50 \\
Sunny & F & 8 & 128 & 160 & 91.67 & 95.83 \\
Capuchins & & & & & & \\
Paté & M & 25 & 48 & 200 & 87.50 & 91.67 \\
R. Hood & M & 19 & 64 & 200 & 91.67 & 91.67 \\
Robot & M & 21 & 128 & 152 & 95.83 & 87.50 \\
Sandokan & M & 16 & 120 & 256 & 91.67 & 95.83 \\
Totò & M & 6 & 72 & 96 & 91.67 & 91.67 \\
Vispo & M & 16 & 72 & 232 & 100.00 & 87.50 \\
Carlotta & F & 32 & 112 & 224 & 95.83 & 87.50 \\
Paprica & F & 27 & 32 & 104 & 87.50 & 91.67 \\
Robinia & F & 23 & 104 & 232 & 87.50 & 91.67 \\
Rucola & F & 16 & 104 & 352 & 87.50 & 87.50 \\
\hline
\end{tabular}

$\mathrm{M}=$ male, $\mathrm{F}=$ female; learning speed = number of trials to achieve the learning criterion; accuracy score = percentage of correct responses at the attainment of the learning criterion; S\&T $=$ Sight and Touch condition; $\mathrm{S}=$ Sight condition. 
compartments) could be visually isolated from the rest of the aviary by means of sliding opaque walls. The parrots were individually tested in one experimental compartment and were visually separated from the other group members during testing (approximately $15 \mathrm{~min}$ ). Coloured leg rings facilitated individual recognition of the birds. Experiments were conducted between 1000 and 1600 hours. All subjects had previously participated in object discrimination tasks (O'Hara et al., 2015; Wein, Gajdon, \& Schwing, 2015). None of the subjects had been tested before with the stimuli used in this study.

\section{Stimuli}

The stimuli consisted of two sets of cylinder-shaped objects (Fig. 1). Set 1 included four white PVC cylinders ( $10 \mathrm{~cm}$ in length $\times 3$ $\mathrm{cm}$ in diameter) with 10 distinct carved ridges on the external surfaces. The shape of the ridge structures differed in each object. Set 2 included four cylinders identical to those of Set 1 but, in this case, they were inserted into transparent tubes $(10.5 \mathrm{~cm}$ in length $\times 4 \mathrm{~cm}$ in diameter). The tubes were made of extruded polymethyl methacrylate (PMMA), commonly known as Plexiglas. This material is clearer than glass and it did not distort the visual appearance of the objects (Fig. 2a, b). In each set, the four cylinders were combined into the same two pairs: Set 1 (Fig. 1a, b: ST1, ST2) and Set 2 (Fig. 1a, b: S1, S2).

Lengthwise, each cylinder had an inner chamber $(6 \mathrm{~cm}$ in length $\times 1 \mathrm{~cm}$ in width) with an opening located at one end of the object. A food item could be hidden inside the chamber (Fig. 1c). Then, the opening was blocked using a short piece of rigid blue polypropylene rope $(9 \mathrm{~cm}$ in length $\times 0.7 \mathrm{~cm}$ in width), which protruded $3 \mathrm{~cm}$ from the object. Removal of the rope required some force, which necessitated that the subject hold the object with the foot while pulling the rope out with the beak. This ensured that all subjects could gain tactile information from the objects during the experiment.

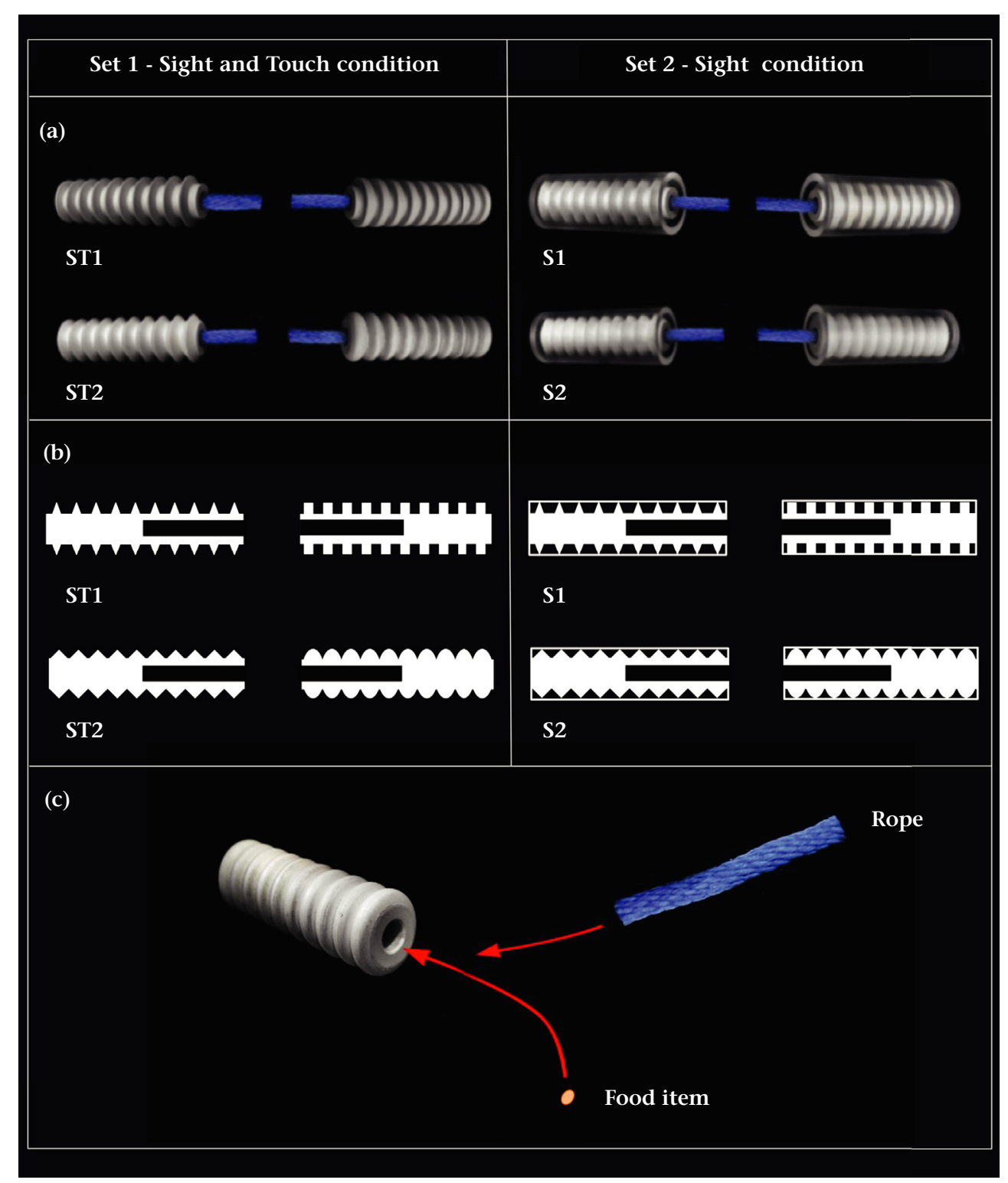

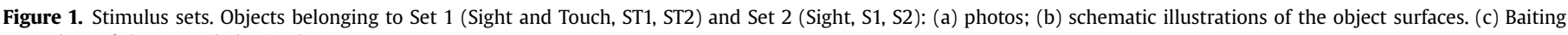
procedure of the rewarded stimulus. 


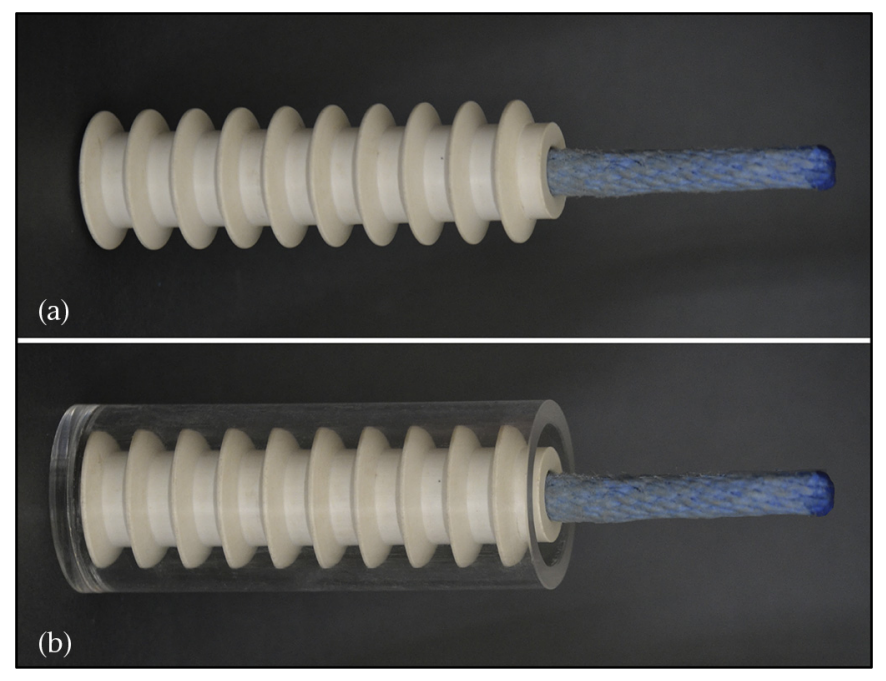

Figure 2. Stimulus details. (a) Example of one stimulus outside the tube and (b) the corresponding stimulus inside the tube.

\section{Experimental Procedure}

A preliminary phase was conducted to verify the kea's proclivity to explore the stimuli and to give them the opportunity to know that objects could contain food items. For this purpose, parrots were allowed to investigate one pair of stimuli of Set 1 and one pair of stimuli of Set 2. In particular, they investigated one stimulus pair of Set 1 and the nonequivalent stimulus pair of Set 2; in this manner, individuals could explore pairs ST1 and S2 or pairs ST2 and S1 (see Fig. 1a, b). These combinations of stimulus pairs avoided interference between the experimental conditions (see below). In this phase, all the objects contained a hidden food item. The kea received each pair of objects twice per day until they were able to remove the rope and retrieve the reward from each of the two objects in a single presentation. This phase lasted 1-3 days.

After the preliminary phase, parrots were trained with the same, previously assigned, pair of stimuli but only one object within the pair contained a reward. Kea had to select the rewarded stimulus $(\mathrm{S}+)$ within each object pair. The type of stimulus pairs (combinations ST1 and S2 or ST2 and S1, Fig. 1a, b) and the S+ within each pair were counterbalanced across subjects. Thus, half of the subjects received combinations ST1 and S2, whereas the other half received combinations ST2 and S1 as type of stimulus pairs. Moreover, within a specific stimulus pair, half of the subjects received one stimulus as $S_{+}$, whereas the other half received the opposite. The parrots had to select from the objects relying only on visual cues. After the choice they were allowed to manipulate the chosen object to gain access to the reward. During the manipulation they were or were not able to acquire additional tactile information on the surface structure of the selected object depending on the experimental condition: in the Sight and Touch condition (objects of Set 1, Fig. 1a, b: ST1, ST2), the parrots could acquire this information, whereas in the Sight condition (objects of Set 2, Fig. 1a, b: S1, S2) they could not since the objects were both inserted into the tubes, resulting in the same uniform surface.

Stimuli were presented to the kea on the ground of the experimental compartment. At the beginning of each trial, the experimenter, out of the subjects' view, inserted a pellet (Nutribird G14 Original, Versele Laga, Deinze, Belgium) into the inner chamber of $\mathrm{S}+$ (Fig. 1c) and blocked the openings of both objects with the ropes. Then, the two objects were placed on the ground equidistant (approximately $1 \mathrm{~m}$ away) from the subject (Fig. 3a). An approximate distance of $20 \mathrm{~cm}$ between the objects was kept constant. The stimuli inserted into tubes (Set 2) were positioned to avoid reflections due to light sources such as direct sunlight. In both experimental conditions, kea expressed their choice by approaching and interacting with one object to remove its rope. Once they made a choice, the experimenter promptly removed the unselected object. To inspect the chosen object for a reward contained within, the kea grasped it with a foot while removing the rope with the beak and then turned it over with coordinated movements of the foot and the beak (Fig. 3b, c). If the bird chose the wrong object, the experimenter opened the unselected object and showed that a reward was hidden inside but did not give the reward to the subject.

The kea received one 16-trial session per day: eight trials in the Sight and Touch condition and eight in the Sight condition. Each $\mathrm{S}+$ was presented an equal number of times in both the right and the left position. Trials were presented in a quasirandom order, with the only constraints being that no more than three consecutive trials were presented in the same condition and no more than two consecutive trials had the $S+$ in the same position. Sessions were administered 6 days per week. In both the Sight and Touch and the Sight condition the learning criterion was achieved when parrots selected $\mathrm{S}+$ of each pair at least seven of eight times for three consecutive sessions (87.5\%; binomial test: $P=0.032$ ). All sessions were video-recorded with an HD camcorder (Canon LEGRIA HF R66).

\section{Ethical note}

The institutional ethics and animal welfare committee at the University of Veterinary Medicine Vienna approved this study (17/ 02/97/2012) in accordance with national legislation (Animal Protection Act, BGBl. I Nr.118/2004, as amended from time to time) and Good Scientific Practice (https://www.vetmeduni.ac.at/fileadmin/ v/z/forschung/GoodScientificPractice_English.pdf). Furthermore, since the present study was based on behavioural observations and was strictly noninvasive, it was classified as a nonanimal experiment in accordance with the Austrian Animal Experiments Act ( $\S 2$, Federal Law Gazette No. 501/1989). The experiment adhered to the ASAB/ABS Guidelines for the Use of Animals in Research.

\section{Data analyses}

Two measures were considered for the analyses: the number of trials to achieve the learning criterion (i.e. learning speed) and the percentage of correct responses at the attainment of the learning criterion (i.e. accuracy score at acquisition). Accuracy score at acquisition was defined as the average percentage of correct responses in the three consecutive training sessions in which the criterion was achieved.

The Kolmogorov-Smirnov test showed that the distributions of data did not deviate significantly from normality (all tests: $P>0.20$ ). Therefore, parametric statistics were used for data analyses. In particular, paired-sample $t$ tests were carried out to evaluate whether the performance in the Sight and Touch condition and in the Sight condition differed in terms of (1) learning speed to achieve the criterion and (2) accuracy score at the attainment of the criterion. Statistical significance was set at $P<0.05$.

\section{Results}

The individual data concerning the number of trials to achieve the learning criterion and the percentage of correct responses at the attainment of the criterion are shown in relation to sex and age in Table 1.

The kea required significantly fewer trials to achieve the learning criterion in the Sight and Touch condition (mean \pm $\mathrm{SE}=122.0 \pm 9.4$ ) than in the Sight condition (mean \pm $\mathrm{SE}=207.0 \pm 9.4 ;$ paired-sample $t$ test: $t_{7}=7.14, \quad P=0.0002$; 


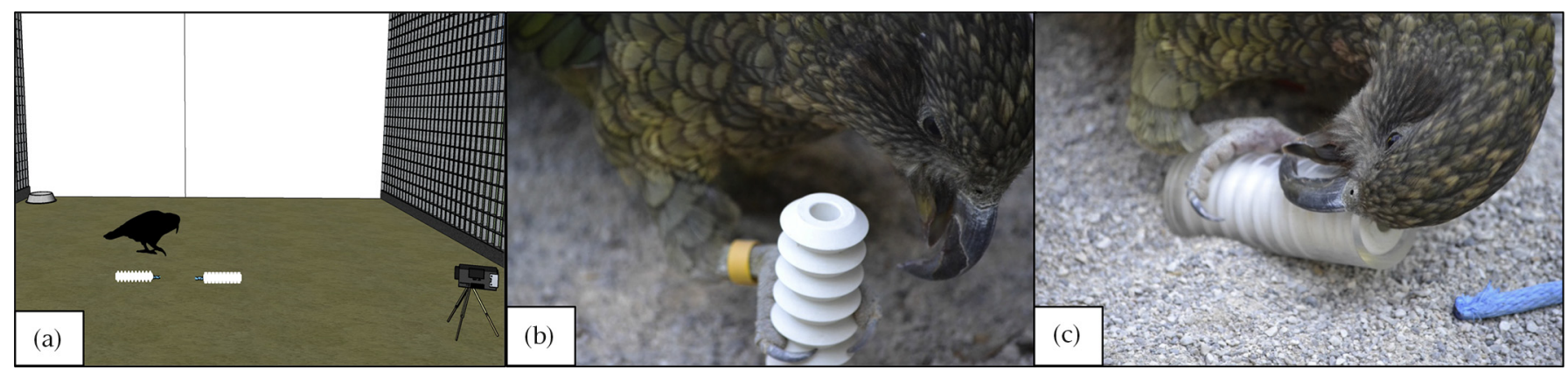

Figure 3. Experimental procedure used with kea. (a) Experimental setting; a male kea explores the object in (b) the Sight and Touch condition and (c) the Sight condition.
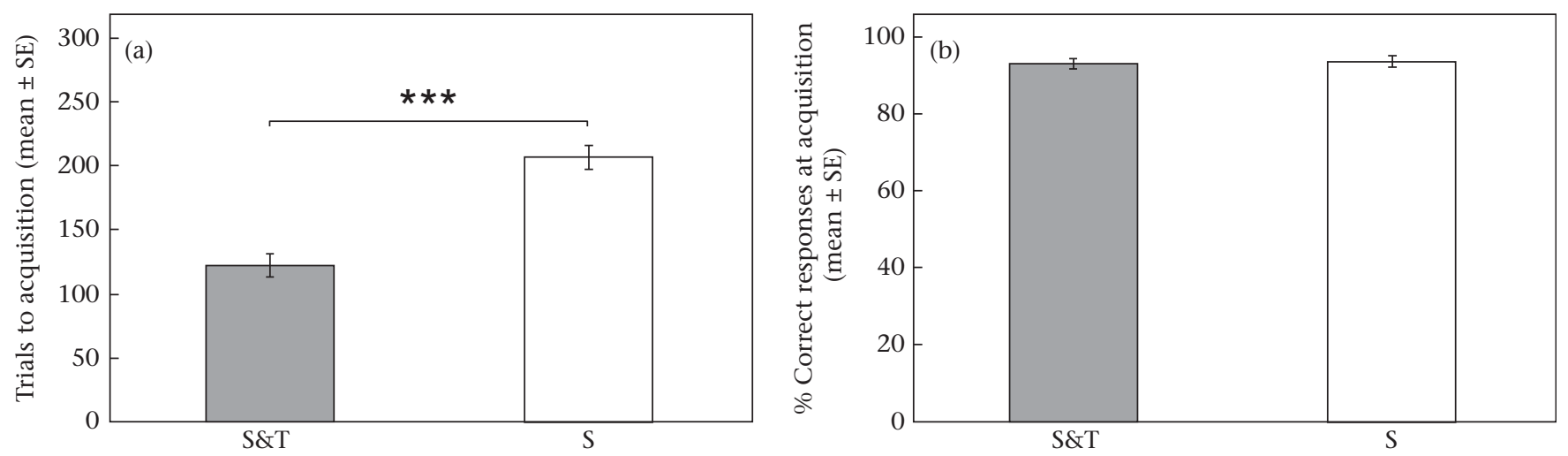

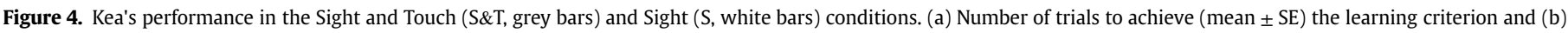
percentage of correct responses (mean $\pm \mathrm{SE}$ ) at the attainment of the learning criterion. Paired-sample $t$ test: ${ }^{* * *} P<0.001$.

Fig. 4a). However, once they had attained the learning criterion there was no significant difference between the accuracy scores at acquisition in the Sight and Touch condition (mean \pm$\mathrm{SE}=93.2 \pm 1.3 \%$ ) and in the Sight condition (mean \pm $\mathrm{SE}=93.8 \pm 1.3 \%$; paired-sample $t$ test: $t_{7}=0.28, P=0.79$; Fig. $4 \mathrm{~b}$ ).

\section{EXPERIMENT ON CAPUCHIN MONKEYS}

\section{Methods}

\section{Subjects and housing conditions}

We tested 10 tufted capuchin monkeys: six males and four females (Table 1). All capuchins were adults (6-32 years old) born in captivity and were unknown combinations of species of the genus Sapajus (Lynch Alfaro, Boubli et al., 2012; Lynch Alfaro, De Souza Silva, \& Rylands 2012). Data based on mitochondrial DNA and phylogenetic analyses (Lucarelli et al., 2017) indicated matrilineal haplotypes corresponding to Sapajus cay $(N=9)$ and Sapajus macrocephalus $(N=1)$. Capuchins belonged to four groups, which were housed in indoor-outdoor facilities (indoor: $5 \mathrm{~m}^{2} \times 2.5 \mathrm{~m}$ high; outdoor: $40-130 \mathrm{~m}^{2} \times 3 \mathrm{~m}$ high) at the Primate Center of the Institute of Cognitive Sciences and Technologies, CNR, Rome, Italy. To improve three-dimensional space accessible to the monkeys, indoor enclosures were equipped with perches and ropes and outdoor enclosures were equipped with logs, branches and ropes. Moreover, outdoor enclosures were provided with natural substrates, including woodchips on the ground, to promote exploratory behaviours. Each indoor facility included two large shelters, an experimental cubicle and an area for the experimenter. Capuchins were individually tested in the cubicle $(180 \times 75 \mathrm{~cm}$ and 75 $\mathrm{cm}$ high; the cubicle floor is $80 \mathrm{~cm}$ higher than the floor of the rest of the room) to which they had access through a sliding door from the adjacent indoor shelter. Subjects were separated from the group just before the daily experimental session solely for testing (approximately $25 \mathrm{~min}$ ). Experiments occurred between 0950 and 1515 hours. Water was freely available. Fresh fruit, vegetables and monkey chow were provided in the afternoon after the experimental activity. All capuchins were accustomed to the experimental cubicle, the experimental routine and the experimenter. Moreover, except for two monkeys (Totò and Robinia), all subjects had taken part in a previous study on object size discrimination where the same experimental setting was used (Truppa et al., 2015). The other monkeys were familiarized with the experimental setting immediately before starting the experiment. None of the subjects had been tested before with the objects used in this study.

\section{Stimuli}

The stimuli used to test capuchins were the same as those used with the kea (Fig. 1).

\section{Experimental setting}

Stimuli were presented to capuchins on the top of two black PVC boards $(20 \times 20 \mathrm{~cm}$ and $0.6 \mathrm{~cm}$ high) that could be slid upon a metal trolley $(59 \times 64 \mathrm{~cm}$ and $92 \mathrm{~cm}$ high; Fig. 5a). A grey PVC plane $(50 \times 53 \mathrm{~cm})$ with two tracks $(20 \times 50 \mathrm{~cm})$ was used to move the boards with the stimuli towards and away from the subject. During object manipulation in the preliminary phase (see Experimental procedure below), capuchins occasionally broke the objects by banging them on the cage floor. Therefore, to prevent capuchins from damaging the stimuli, each object was fastened to the board by means of a transparent thread ( $14 \mathrm{~cm}$ in length) and a snap-hook ( $4 \mathrm{~cm}$ in length, Fig. 5a: 1 ). This allowed monkeys to manipulate the selected object without being able to take it away. The trolley was 


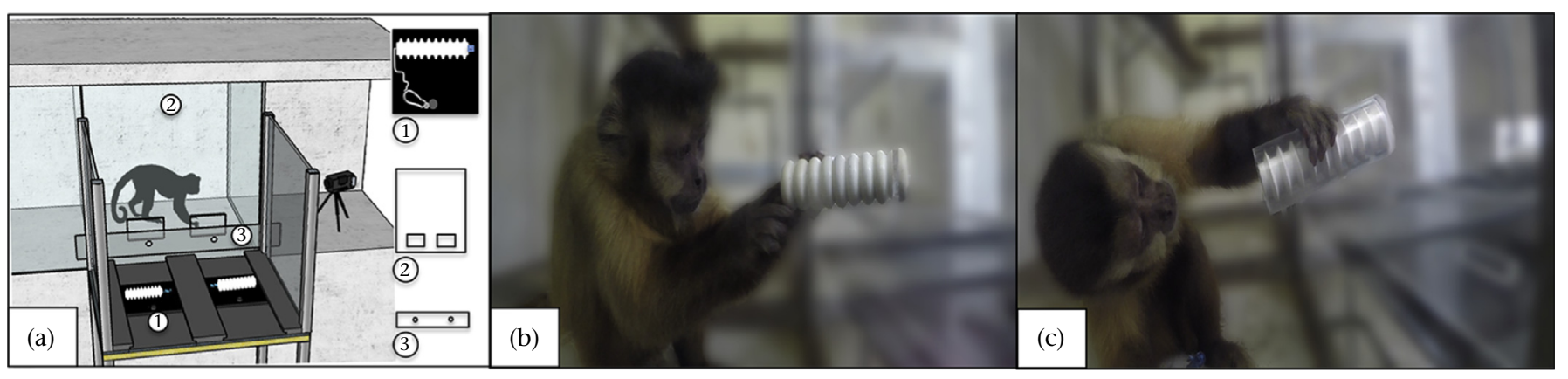

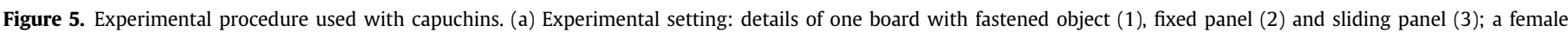
capuchin monkey explores the object in (b) the Sight and Touch condition and (c) the Sight condition.

installed in front of the experimental cubicle, behind two transparent Plexiglas panels used as barriers between the monkey and the objects: one fixed panel $(56 \times 73 \mathrm{~cm})$, with two rectangular openings $(14 \times 5.5 \mathrm{~cm})$ at the bottom, was mounted on the central front wall of the cubicle (Fig. 5a: 2); and one sliding panel $(64 \times 9$ $\mathrm{cm}$ ) with two holes $(1.5 \mathrm{~cm}$ in diameter) was installed on the front part of the trolley (Fig. 5a: 3).

\section{Experimental procedure}

The experimental design was the same as that adopted for the kea. Before starting the experiment, a preliminary phase was conducted to verify capuchins' proclivity to explore the stimuli and to give them the opportunity to know that objects could contain food items. For this purpose, capuchins were allowed to investigate one stimulus pair of Set 1 and the nonequivalent stimulus pair of Set 2 . In this phase, all the objects contained a hidden food item. Capuchins received each pair of objects twice per day until they were able to remove the rope and retrieve the reward from each of the two objects in a single presentation. This phase lasted 1-3 days.

After the preliminary phase, as for kea, capuchins were trained with the same, previously assigned, pair of stimuli but only one object within the pair contained a reward. They had to select the S+ within each object pair. Capuchins selected the objects relying only on visual information and, after the choice, they could acquire additional tactile information on the chosen object's surface (Sight and Touch condition) or not (Sight condition).

At the beginning of each trial, the experimenter, out of the subject's view, inserted a little piece of peanut into the inner chamber of S+ (Fig. 1c) and blocked the openings of both the objects with the ropes. Then, the threads of the objects were secured to the PVC boards, which were placed inside the tracks on the trolley. The stimuli inserted into tubes (Set 2) were positioned to avoid reflections due to light sources such as brightly focused indoor lights. The objects were simultaneously moved slowly forwards within arm's reach of the subject when it positioned itself in front of the apparatus. In the experimental conditions, the monkey made a choice by inserting a finger into the hole of the sliding panel spatially corresponding with the chosen object. After the choice, the experimenter moved the board with the unselected stimulus away and removed the sliding panel, thus allowing the monkey to directly explore the chosen object by inserting its arms through the rectangular opening of the fixed panel (Fig. 5a). To inspect the chosen object, capuchins grasped it with one or two hands while removing its rope with the other hand or the mouth and then turned it over or rolled it with coordinated movements of the hands (Fig. 5b, c). If the monkey chose the wrong object, the experimenter opened the unselected object and showed that a reward was hidden inside but did not give the reward to the subject.
Number and order of trials, learning criterion and video recording were the same as those used to test the kea.

\section{Ethical note}

The data collection conducted on capuchin monkeys and the research protocol were approved by the Italian Health Ministry (Central Direction for the Veterinary Service, approval n. DM132/ 2014-C to V. Truppa). Housing conditions and experimental procedures were in full accordance with European law on humane care and use of laboratory animals and complied with the recommendations of the Weatherall Report (Weatherall, 2006). The experiment adhered to the ASAB/ABS Guidelines for the Use of Animals in Research.

\section{Data analyses}

As in the experiment with kea, the measures considered for the analyses were the learning speed and the accuracy score at acquisition.

The Kolmogorov-Smirnov test showed that the distributions of data did not deviate significantly from normality (all tests: $P>0.20$ ). Therefore, parametric paired-sample $t$ tests were carried out to evaluate whether capuchins' performance in the Sight and Touch condition and in the Sight condition differed in terms of (1) learning speed to achieve the criterion and (2) accuracy score at the attainment of the criterion. Statistical significance was set at $P<0.05$.

\section{Results}

The individual data concerning the number of trials to achieve the learning criterion and the percentage of correct responses at the attainment of the criterion are shown in relation to sex and age in Table 1.

The capuchins required significantly fewer trials to achieve the learning criterion in the Sight and Touch condition (mean \pm $\mathrm{SE}=85.6 \pm 10.3$ ) than in the Sight condition (mean \pm $\mathrm{SE}=204.8 \pm 23.8$; paired-sample $t$ test: $t_{9}=5.63, P=0.0003$; Fig. 6a). However, once they had attained the learning criterion there was no significant difference between the accuracy scores at acquisition in the Sight and Touch condition (mean \pm $\mathrm{SE}=91.7 \pm 1.4 \%$ ) and in the Sight condition (mean \pm $\mathrm{SE}=90.4 \pm 0.9 \%$; paired-sample $t$ test: $t_{9}=0.63, P=0.54$; Fig. $6 \mathrm{~b}$ ).

\section{Comparison Across Species}

To analyse possible differences in performance between kea and capuchin monkeys, a mixed-effects ANOVA model was carried out on the learning speed and the accuracy score at acquisition of the 

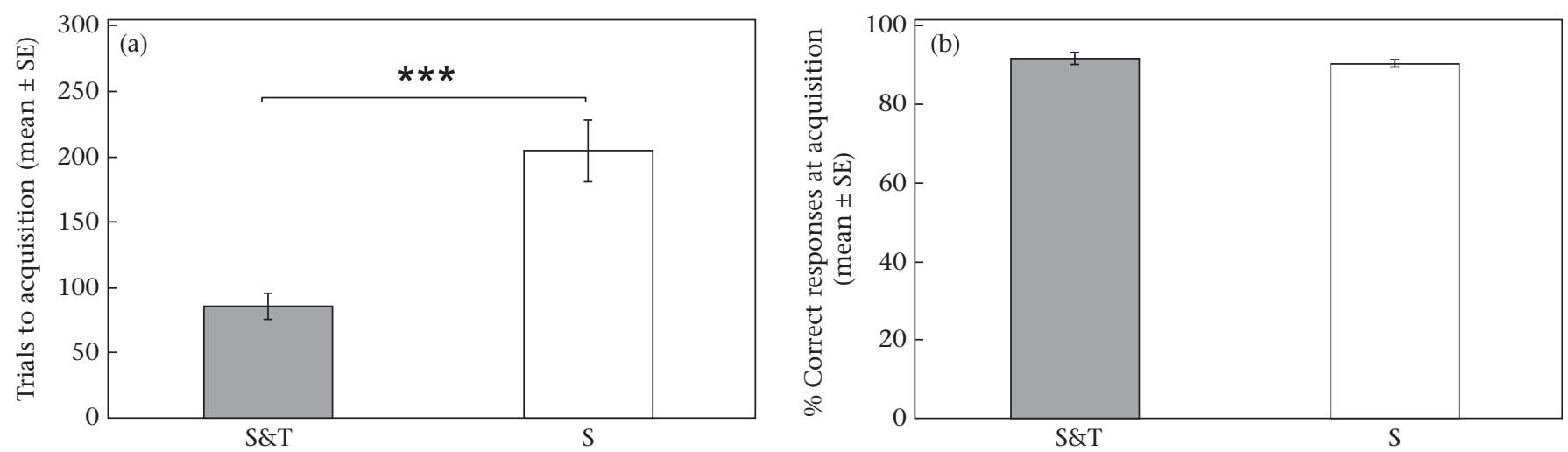

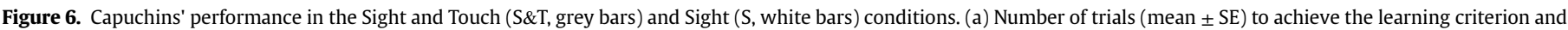
(b) percentage of correct responses (mean $\pm \mathrm{SE}$ ) at the attainment of the learning criterion. Paired-sample $t$ test: ${ }^{* * *} P<0.001$.

two species. The ANOVAs included the Experimental condition (Sight and Touch; Sight) as a within-subjects factor and Species, Object pair of each set and $\mathrm{S}+$ within each pair as between-subjects factors. Statistical significance was set at $P<0.05$.

Concerning the learning speed, a significant main effect of the Experimental condition was found $\left(F_{1,10}=68.04, P=0.00001\right.$, $\eta_{p}^{2}=0.872$ ). Therefore, consistent with results from the separate analyses for the two species, the ANOVA confirmed that, overall, individuals of both species required significantly fewer trials to achieve the learning criterion in the Sight and Touch condition (mean $\pm \mathrm{SE}=101.8 \pm 8.2$ ) than in the Sight condition (mean \pm $\mathrm{SE}=205.8 \pm 13.5)$. No other significant main effects or interactions due to Species, Object pair and S+ were found. A summary of the results is provided in Appendix Table A1.

Regarding the accuracy score at acquisition, consistent with results of separate analyses for the two species, no main effect of the Experimental condition was found (Sight and Touch: mean $\pm S E=92.4 \pm 1.0 \%$; $\quad$ Sight: $\quad$ mean $\pm S E=91.9 \pm 0.9 \%$; $\left.F_{1,10}=0.10, P=0.76\right)$. No other significant main effects or interactions due to Species, Object pair and $\mathrm{S}+$ were found. A summary of the results is provided in Appendix Table A1.

\section{DISCUSSION}

The present study demonstrated that tactile information improves visual object discrimination in kea and capuchin monkeys. In accordance with our predictions, both species benefited from gaining additional tactile information about the object's surface structure. Both kea and capuchins learned to solve the task in fewer trials when they were allowed to perceive the differing surfaces both visually and haptically (Sight and Touch condition) than when they were prevented from touching them (Sight condition); yet, at the attainment of the learning criterion, they showed comparable levels of accuracy in the two conditions. Moreover, the two species took advantage of the tactile information in a comparable way.

The fact that both kea and capuchins needed significantly fewer presentations in the Sight and Touch condition than in the Sight condition indicates that (1) these stimuli were more easily recalled than the objects presented in the Sight condition and, more importantly, that (2) these animals were able to use visuotactile information and memories about the object to solve the task. In this study, we used a two-alternative forced-choice task in which only visual cues were available to the subjects during object choice. In the Sight and Touch condition, after choosing an object, subjects could acquire and retain distinctive tactile information on the selected object in addition to the distinctive visual information, which could then be used to identify the rewarded object in the next visual presentation of the same object pair. In contrast, in the Sight condition they could perceive and retain only visual information because the objects were presented in transparent tubes, making the surfaces of both objects haptically identical. In other words, during the experiment, whereas in the Sight and Touch condition subjects could store both visual and tactile memories of differences between the objects, in the Sight condition they could store only visual memories. Thus, although the object discrimination was performed only using the visual modality in both experimental conditions, it is reasonable to assume that in the Sight and Touch condition the retrieval of the stored tactile information supported discrimination processes in the visual modality. Hence, our study revealed that visuotactile integration can enhance the subsequent unisensory visual recognition and it expands on previous findings demonstrating cross-modal transfer of information between sight and touch in nonhuman species (e.g. Cowey \& Weiskrantz, 1975; Davenport \& Rogers, 1970; Elliott, 1977; Petrides \& Iversen, 1976; Reid et al., 2012, 2013; Weiskrantz \& Cowey, 1975; Winters \& Reid, 2010; for a review see Cloke et al., 2015).

A further comment should be made on the implications of the procedure we used. First, the fact that both kea and capuchins achieved comparable accuracy scores at acquisition in the two conditions indicates that the Plexiglas tubes did not distort the visual appearance of the objects. Indeed, distortions due to the tubes would imply that visual constraints would be the same throughout the experiment, resulting in a high number of errors even after long training. In contrast, our results on the accuracy scores at acquisition indicate that, although subjects needed more trials in the Sight than in the Sight and Touch condition, kea and capuchins achieved a comparable percentage of correct responses in both conditions. Second, our procedure allowed individuals to handle the selected object in both Sight and Touch and Sight conditions. Distinctive visual and tactile information was available during object handling in the Sight and Touch condition. In contrast, in the Sight condition, only distinctive visual information was available since the smooth Plexiglas tubes provided uniform tactile input. It would be interesting to further investigate whether perceiving the ridge structures of a surface in the visual modality and a uniform surface in the tactile modality produces a sensory conflict and to what extent it interferes with learning.

The idea that information from touch is used to calibrate and fine-tune visual capabilities has found support in human research (Gori, Tinelli, Sandini, Cioni, \& Burr, 2012; Wallraven et al., 2014). Human adults, for example, when trained to discriminate shape 
categories by touch, improved their ability to visually discriminate the same stimuli and vice versa, indicating bidirectional performance enhancement by transfer of implicit knowledge across modalities (Wallraven et al., 2014). More generally, multisensory experience has been proven to enhance unisensory processing and memory performance in humans (e.g. Butler \& James, 2011; Lehmann \& Murray, 2005; Shams \& Seitz, 2008; Thelen, Cappe, \& Murray, 2012). For instance, Lehmann and Murray (2005) found that repeated images are discriminated better when presented to the participants as audiovisual stimuli, rather than as visual stimuli only. A similar multisensory enhancement of memory traces in humans might also be assumed when visuotactile stimuli are used (Gallace \& Spence, 2008, 2014). Evidence that multisensory experiences overcome unisensory processing and memory performance has also been found in species phylogenetically very distant from humans (Guo \& Guo, 2005; Rowe, 2002; Steck, Hansson, \& Knaden, 2011; for a review see; Rowe, 2005). For example, Steck et al. (2011) found that desert ants, Cataglyphis fortis, were slow to learn the location of the nest when it was specified by an olfactory or a visual cue alone, whereas the ants focused their nest search after the first training run with the combined cues. Taken together, these findings indicate that investigating learning abilities under conditions of multisensory stimulus presentation is a more ecologically valid approach than focusing on single sensory modalities.

Despite their phylogenetic distance and the constraints due to their different morphology, kea and capuchin monkeys behaved similarly in both the Sight and Sight and Touch conditions. Our findings are consistent with previous studies hypothesizing that these two species can profit from the haptic experience gained during the discrimination of 3D stimuli (O'Hara et al., 2015; Truppa et al., 2015). The present study indicated that, for those species that tend to explore objects by handling them, tactile feedback acquired from the direct haptic exploration of the stimuli is crucial to improve visual judgements. Several analogies between kea and capuchins can contribute to their proficiency in using tactile input to discriminate objects in the environment. First, these species are equipped with anatomical effectors suited to perform complex object manipulation. Notably, kea, as well as other psittaciforms, use zygodactylous feet together with beak and tongue to manipulate objects (Demery, Chappell, \& Martin, 2011; Diamond \& Bond, 1999; Harris, 1989) and capuchin monkeys possess a high degree of manual dexterity (Christel \& Fragaszy, 2000; Costello \& Fragaszy, 1988; Spinozzi, Truppa, \& Laganà, 2004; Spinozzi, Laganà, \& Truppa, 2007; Truppa, Spinozzi, Laganà, Piano Mortari, \& Sabbatini, 2016). Second, both kea (Auersperg, Gajdon, \& Huber, 2009; Huber \& Gajdon, 2006; Huber, Rechberger, \& Taborsky, 2001) and capuchins (Fragaszy et al., 2004; Schrauf, Huber, \& Visalberghi, 2008) possess a strong proclivity to explore objects. Moreover, both species are extractive foragers (Huber \& O'Hara, 2016) capable of exploiting hidden and encased foods (e.g. Diamond \& Bond, 1999; Fragaszy et al., 2004; Greer, Gajdon, \& Nelson, 2015; Visalberghi et al., 2016). However, to clarify whether the anatomical, behavioural and ecological features of species can be related to their ability to exploit tactile information, further studies should be conducted on other taxa, including species that differ in their ability and tendency to manipulate objects. Overall, our study provides the first evidence of visuotactile integration in birds and adds to an increasing body of literature showing that parrots and primates share comparable cognitive skills (Emery \& Clayton, 2004; Güntürkün \& Bugnyar, 2016; Güntürkün, 2012; Lefebvre, Reader, \& Sol, 2004) and highly developed motor skills to manipulate objects and to solve complex manipulation tasks (Brunon, Bovet, Bourgeois, \& Pouydebat, 2014).

Our findings on kea and capuchin monkeys stimulate important questions on the integration of visual and tactile information that need to be addressed in future comparative studies. It would be important to evaluate, for example, whether the acquisition of input from the sense of touch can differently impact the ability to visually recognize objects in relation to the degree of dexterity of different taxonomic groups in manipulating objects. Another challenge is to investigate whether this benefit exists when other physical properties of the objects, such as size and shape, must be discriminated. Finally, further studies are required to determine the extent to which the manipulation patterns used and the length of time spent manipulating the object affect the acquisition of tactile information and the retention of tactile memory.

\section{Acknowledgments}

We are grateful to the Editor and two anonymous referees for their thoughtful suggestions and constructive comments on the manuscript. We thank Amelia Wein, Andrea Piseddu and Tilmann Lange for help with data collection on the kea; Florian Vogel and Sabine Viemann for their help with the kea's management; and András Peter and Markus Fitzka for their technical support. We are also grateful to Valerio Squillace for help with data collection on capuchins; Arianna Manciocco, Massimiliano Bianchi and Simone Catarinacci for help with capuchins' management; and Luigi Carducci and Massimiliano Bianchi for their technical support. We also thank the Comune di Roma-Museo Civico Zoologia and the Fondazione Bioparco for hosting the Unit of Cognitive Primatology and the Primate Center. P.C. received a grant (Short-Term Mobility Program 2015) from the National Research Council of Italy to carry out the experiment at the Haidlhof Research Station of the Messerli Research Institute (University of Veterinary Medicine, Vienna).

\section{References}

Auersperg, A. M. I., Gajdon, G. K., \& Huber, L. (2009). Kea (Nestor notabilis) consider spatial relationships between objects in the support problem. Biology Letters, 5(4), 455-458. https://doi.org/10.1098/rsbl.2009.0114.

Berkeley, G. (1709). An essay towards a new theory of vision. Dublin, Ireland: Pepyat. Brunon, A., Bovet, D., Bourgeois, A., \& Pouydebat, E. (2014). Motivation and manipulation capacities of the blue and yellow macaw and the tufted capuchin: A comparative approach. Behavioural Process, 107, 1-14.

Butler, A. J., \& James, K. H. (2011). Cross-modal versus within-modal recall: Differences in behavioral and brain responses. Behavioural Brain Research, 224 387-396.

Christel, M. I., \& Fragaszy, D. M. (2000). Manual function in Cebus apella. Digital mobility, preshaping, and endurance in repetitive grasping. International Journal of Primatology, 21, 697-719.

Cloke, J. M., Jacklin, D. L., \& Winters, B. D. (2015). The neural bases of crossmoda object recognition in non-human primates and rodents: A review. Behavioural Brain Research, 285, 118-130.

Costello, M. B., \& Fragaszy, D. M. (1988). Prehension in Cebus and Saimiri: I. Grip type and hand preference. American Journal of Primatology, 15, 235-245.

Cowey, A., \& Weiskrantz, L. (1975). Demonstration of cross-modal matching in rhesus monkeys, Macaca mulatta. Neuropsychologia, 13, 117-120.

Davenport, R. K., \& Rogers, C. M. (1970). Intermodal equivalence of stimuli in apes. Science, 168, 279-280.

Davenport, R. K., Rogers, C. M., \& Russell, I. S. (1975). Cross-modal perception in apes: Altered visual cues and delay. Neuropsychologia, 13, 229-235.

Demery, Z. P., Chappell, J., \& Martin, G. R. (2011). Vision, touch and object manipulation in Senegal parrots Poicephalus senegalus. Proceedings of the Royal Society B, 278(1725), 3687-3693. https://doi.org/10.1098/rspb.2011.0374.

Diamond, J., \& Bond, A. B. (1999). Kea, Bird of Paradox: The Evolution and Behavior of a New Zealand Parrot. Berkley, CA: University of California Press.

Elliott, R. C. (1977). Cross-modal recognition in three primates. Neuropsychologia, 15 , $183-186$.

Emery, N. J., \& Clayton, N. S. (2004). The mentality of Crows: Convergent evolution of intelligence in corvids and apes. Science, 306, 1903-1907. https://doi.org/ 10.1126/science.1098410.

Ernst, M. O., \& Banks, M. S. (2002). Humans integrate visual and haptic information in a statistically optimal fashion. Nature, 415, 429-433.

Fragaszy, D. M., Visalberghi, E., \& Fedigan, L. M. (2004). The complete capuchin: the biology of the genus Cebus. Cambridge, U.K.: Cambridge University Press.

Gallace, A., \& Spence, C. (2008). The cognitive and neural correlates of "tactile consciousness": A multisensory perspective. Consciousness and Cognition, 17, 370-407. https://doi.org/10.1016/j.concog.2007.01.005. 
Gallace, A., \& Spence, C. (2014). In touch with the future: The sense of touch from cognitive neurosciences to virtual reality. Oxford, U.K.: Oxford University Press.

Gori, M., Tinelli, F., Sandini, G., Cioni, G., \& Burr, D. (2012). Impaired visual sizediscrimination in children with movement disorders. Neuropsychologia, 50, $1838-1843$.

Greer, A. L., Gajdon, G. K., \& Nelson, X. J. (2015). Intraspecific variation in the foraging ecology of kea, the world' s only mountain- and rainforest-dwelling parrot. New Zealand Journal of Ecology, 39, 254.

Güntürkün, O. (2012). The convergent evolution of neural substrates for cognition. Psychological Research, 76, 212-219. https://doi.org/10.1007/s00426-011-0377-9.

Güntürkün, O., \& Bugnyar, T. (2016). Cognition without cortex. Trends in Cognitive Sciences, 20, 291-303. https://doi.org/10.1016/j.tics.2016.02.001.

Guo, J., \& Guo, A. (2005). Crossmodal interactions between olfactory and visual learning in Drosophila. Science, 309, 307-310.

Harris, L. J. (1989). Footedness in parrots: Three centuries of research, theory, and mere surmise. Canadian Journal of Psychology, 43, 369-396.

Huber, L., \& Gajdon, G. K. (2006). Technical intelligence in animals: The kea model. Animal Cognition, 9(4), 295-305.

Huber, L., \& O'Hara, M. (2016). The extractive foraging hypothesis (Parker and Gibson 1997, 2015). In T. K. Shackelford, \& V. A. Weekes-Shackelford (Eds.) Encyclopedia of Evolutionary Psychological Science. New York, NY: Springer.

Huber, L., Rechberger, S., \& Taborsky, M. (2001). Social learning affects object exploration and manipulation in keas, Nestor notabilis. Animal Behaviour, 62(5) 945-954.

Lacey, S., Peters, A., \& Sathian, K. (2007). Cross-modal object representation is viewpoint-independent. PLOS ONE, 2, e890.

Lawson, R. (2009). A comparison of the effects of depth rotation on visual and haptic three-dimensional object recognition. Journal of Experimental Psychology: Human Perception and Performance, 35, 911-930.

Lefebvre, L, Reader, S. M. \& Sol, D. (2004). Brains, innovations and evolution in birds and primates. Brain, Behavior and Evolution, 63, 233-246. https://doi.org/ $10.1159 / 000076784$.

Lehmann, S., \& Murray, M. M. (2005). The role of multisensory memories in unisensory object discrimination. Cognitive Brain Research, 24, 326-334.

Lucarelli, M., Visalberghi, E., Adriani, W., Addessi, E., Pierandrei, S., Manciocco, A. et al. (2017). Polymorphism of the 3'-UTR of the dopamine transporter gene (DAT) in New World monkeys. Primates, 58, 169-178. https://doi.org/10.1007/ s10329-016-0560-0.

Lynch Alfaro, J. W., Boubli, J. P., Olson, L. E., Di Fiore, A., Wilson, B., GutiérrezEspeleta, G. A., et al. (2012a). Explosive Pleistocene range expansion leads to widespread Amazonian sympatry between robust and gracile capuchin monkeys. Journal of Biogeography, 39, 272-288. https://doi.org/10.1111/j.13652699.2011.02609.x.

Lynch Alfaro, J. W., De Souza Silva, J., \& Rylands, A. B. (2012b). How different are robust and gracile capuchin monkeys? An argument for the use of Sapajus and Cebus. American Journal of Primatology, 74, 273-286. https://doi.org/10.1002/ ajp.22007.

Norman, J., Norman, H., Clayton, A., Lianekhammy, J., \& Zielke, G. (2004). The visua and haptic perception of natural object shape. Perception and Psychophysics, 66 342-351.

O'Hara, M. Mioduszewska, B, von Bayern, A, Auersperg A, Bugnyar, T, Wilkinson, A., et al. (2017). The temporal dependence of exploration on neotic style in birds. Scientific Reports, 7, 4742. https://doi.org/10.1038/s41598-01704751-0.

O'Hara, M., Huber, L., \& Gajdon, G. K. (2015). The advantage of objects over images in discrimination and reversal learning by kea, Nestor notabilis. Animal Behaviour 101, 51-60.

Petrides, M., \& Iversen, S. (1976). Cross-modal matching and the primate frontal cortex. Science, 192, 1023-1024.

Reid, J. M., Jacklin, D. L., \& Winters, B. D. (2012). Crossmodal object recognition in rats with and without multimodal object pre-exposure: No effect of hippocampal lesions. Neurobiology of Learning and Memory, 98, 311-319.

Reid, J. M., Jacklin, D. L., \& Winters, B. D. (2013). Delineating prefrontal cortex region contributions to crossmodal object recognition in rats. Cerebral Cortex, 24, 2108 2019.

Rowe, C. (2002). Sound improves visual discrimination learning in avian predators. Proceedings of the Royal Society B, 269, 1353-1357.

Rowe, C. (2005). Multisensory learning: From experimental psychology to animal training. Anthrozoös, 18(3), 222-235.

Schrauf, C., Huber, L., \& Visalberghi, E. (2008). Do capuchin monkeys use weight to select hammer tools? Animal Cognition, 11, 413-422. https://doi.org/10.1007| s10071-007-0131-2.

Shams, L., \& Seitz, A. (2008). Benefits of multisensory learning. Trends in Cognitive Sciences, 12, 411-417. https://doi.org/10.1016/j.tics.2008.07.006.

Spinozzi, G., Laganà, T., \& Truppa, V. (2007). Hand use by tufted capuchins (Cebus apella) to extract a small food item from a tube: Digit movements, hand preference, and performance. American Journal of Primatology, 69, 336-352.

Spinozzi, G., Truppa, V., \& Laganà, T. (2004). Grasping behavior in tufted capuchin monkeys (Cebus apella): Grip types and manual laterality for picking up a small food item. American Journal of Physical Anthropology, 125, 30-41.

Steck, K., Hansson, B. S., \& Knaden, M. (2011). Desert ants benefit from combining visual and olfactory landmarks. Journal of Experimental Biology, 214, 1307-1312. https://doi.org/10.1242/jeb.053579.
Stein, B. E., \& Meredith, M. A. (1993). The merging of the senses. Cambridge, MA: MIT Press.

Thelen, A., Cappe, C., \& Murray, M. M. (2012). Electrical neuroimaging of memory discrimination based on single-trial multisensory learning. Neurolmage, 62, $1478-1488$.

Truppa, V., Carducci, P., Trapanese, C., \& Hanus, D. (2015). Does presentation format influence visual size discrimination in tufted capuchin monkeys (Sapajus spp.)? PLoS ONE, 10(4), e0126001.

Truppa, V., Spinozzi, G., Laganà, T., Piano Mortari, E., \& Sabbatini, G. (2016). Versatile grasping ability in power-grip actions by tufted capuchin monkeys (Sapajus spp.). American Journal of Physical Anthropology, 159, 63-72. https://doi.org/ 10.1002/ajpa.22836.

Visalberghi, E., Albani, A., Ventricelli, M., Izar, P., Schino, G., \& Fragazsy, D. (2016). Factors affecting cashew processing by wild bearded capuchin monkeys (Sapajus libidinosus, Kerr 1792). American Journal of Primatology, 78, 799-815. https://doi.org/10.1002/ajp.22545.

Wallraven, C., Bülthoff, H. H., Waterkamp, S., van Dam, L., \& Gaißert, N. (2014). The eyes grasp, the hands see: Metric category knowledge transfers between vision and touch. Psychonomic Bulletin \& Review, 21, 976-985. https://doi.org/10.3758/ s13423-013-0563-4. PMID: 24307250.

Weatherall, D. (2006). The use of non-human primates in research: A working group report. http://www.acmedsci.ac.uk/viewFile/publicationDownloads/1165861003.pdf.

Wein, A., Gajdon, G. K., \& Schwing, R. (2015). Picture - object recognition in kea (Nestor notabilis). Ethology, 121, 1-12.

Weiskrantz, L., \& Cowey, A. (1975). Cross-modal matching in the rhesus monkey using a single pair of stimuli. Neuropsychologia, 13, 257-261.

Winters, B. D., \& Reid, J. M. (2010). A distributed cortical representation underlies cross-modal object recognition in rats. Journal of Neuroscience, 30, 6253-6261.

Yildirim, I., \& Jacobs, R. A. (2013). Transfer of object category knowledge across visual and haptic modalities: Experimental and computational studies. Cognition, 126, 135-148. https://doi.org/10.1016/j.cognition.2012.08.005.

\section{Appendix}

\section{Table A1}

Summary of the main effects and interactions of the mixed-effects ANOVAs on the learning speed and the accuracy score at acquisition

\begin{tabular}{|c|c|c|c|}
\hline Effect & $d f$ & $F$ & $P$ \\
\hline \multicolumn{4}{|l|}{ Learning speed } \\
\hline Object pair & 1,10 & 0.002 & 0.962 \\
\hline $\mathrm{S}+$ & 1,10 & 0.228 & 0.644 \\
\hline Species & 1,10 & 1.007 & 0.339 \\
\hline Experimental condition & 1,10 & 68.036 & $<0.001$ \\
\hline Object pair*S+ & 1,10 & 0.243 & 0.632 \\
\hline Object pair*Species & 1,10 & 1.646 & 0.228 \\
\hline $\mathrm{S}+{ }^{*}$ Species & 1,10 & 0.001 & 0.974 \\
\hline Object pair*S+*Species & 1,10 & 0.295 & 0.599 \\
\hline Experimental condition*Object pair & 1,10 & 1.290 & 0.283 \\
\hline Experimental condition* $\mathrm{S}+$ & 1,10 & 0.047 & 0.833 \\
\hline Experimental condition*Species & 1,10 & 1.828 & 0.206 \\
\hline Experimental condition*Object pair*S+ & 1,10 & 0.797 & 0.393 \\
\hline Experimental condition*Object pair*Species & 1,10 & 4.799 & 0.053 \\
\hline Experimental condition $* \mathrm{~S}+{ }^{*}$ Species & 1,10 & 0.018 & 0.895 \\
\hline Experimental condition*Object pair*S $+{ }^{*}$ Species & 1,10 & 0.105 & 0.752 \\
\hline \multicolumn{4}{|l|}{ Accuracy score at acquisition } \\
\hline Object pair & 1,10 & 0.006 & 0.941 \\
\hline $\mathrm{S}+$ & 1,10 & 0.973 & 0.347 \\
\hline Species & 1,10 & 3.596 & 0.087 \\
\hline Experimental condition & 1,10 & 0.099 & 0.760 \\
\hline Object pair*S + & 1,10 & 1.662 & 0.226 \\
\hline Object pair*Species & 1,10 & 0.144 & 0.713 \\
\hline $\mathrm{S}+{ }^{*}$ Species & 1,10 & 2.080 & 0.180 \\
\hline Object pair*S $+{ }^{*}$ Species & 1,10 & 0.971 & 0.348 \\
\hline Experimental condition*Object pair & 1,10 & 0.099 & 0.759 \\
\hline Experimental condition* $\mathrm{S}_{+}$ & 1,10 & 0.476 & 0.506 \\
\hline Experimental condition*Species & 1,10 & 0.478 & 0.505 \\
\hline Experimental condition*Object pair*S+ & 1,10 & 2.468 & 0.147 \\
\hline Experimental condition*Object pair*Species & 1,10 & 2.088 & 0.179 \\
\hline Experimental condition ${ }^{*} S+{ }^{*}$ Species & 1,10 & 1.429 & 0.260 \\
\hline Experimental condition*Object pair*S+ $+{ }^{*}$ Species & 1,10 & 0.099 & 0.760 \\
\hline
\end{tabular}

Object pair of each set (combinations: ST1, S2; ST2, S1), S+ within each pair and Species (kea; capuchin monkey) were included as between-subjects factors. Experimental condition (Sight and Touch; Sight) was included as a within-subjects factor. 